\title{
LIBROS
}





\section{CELSO SÁNCHEZ CAPDEQUÍ (2017): La creatividad social: narra- tivas de un concepto actual, Madrid: Centro de Investigaciones Socio- lógicas: Colección Academia. 487 pags.}

En el meridiano de los años setenta del pasado siglo, el sociólogo norteamericano, no siempre justamente tratado por el encasillamiento académico, Daniel Bell diagnosticaba un décalage crucial en el corazón de la cultura norteamericana aparecido a inicios de los sesenta: el existente entre el orden técnico-económico y el cultural, el de la racionalidad instrumental en donde se mueven las instituciones y el de un yo por excelencia volcado hacia la apropiación de una hybris estética violadora de los viejos valores ascéticos, tan fielmente retratados en otra hora por Max Weber, en los que se incardinara originariamente el capitalismo. A tenor de ello, la conquista de un yo expresivo que hace acopio de su singularidad deviene un leitmotiv identitario que inunda la fisonomía de una naciente modulación cultural, debiendo sortear en este empeño diversos obstáculos, de los cuales el más relevante habría sido un tipo de moral vista de suyo en clave coercitiva. Bell lo resumía así: «El modernismo tradicional trató de sustituir la religión o la moralidad por una justificación estética de la vida. Crear una obra de arte, ser una obra de arte: solo esto daba sentido al esfuerzo del hombre por trascenderse» (Bell, Las contradicciones culturales del capitalismo, Madrid, Alianza, 1987: 6061). En realidad, la radicalidad de esta tematización fue preconcebida y auspi- ciada casi un siglo antes, notoriamente evidenciado la erosión de los pilares sobre los que se sostuvieran las orientaciones de sentido sustantivas de raigambre cristiana. Friedrich Nietzsche ya había exhortado, en esta línea, al abrazo de un "nihilismo activo". Para él, definitivamente disueltas las certezas ontológicas gestadas en el platonismo, luego prolongadas en el cristianismo y metamorfoseadas secularmente en la modernidad, solo cabría asumir un precario horizonte de verdad futuro en virtud de una potencia inspirada por la voluntad singularmente creadora de valores albergada en el ser humano. Huelga decir que el "nihilismo activo" no busca realzar una mera ornamentación estética de la vida. Consiste en un encaramiento, en términos artísticos, frente al designio cultural al cual se ven abocadas las sociedades occidentales. Encaramiento arrastrado por un compromiso con la creación de valores surgidos de una afirmación de la vida en su condición más individualizada. El lema basado en la extensión del arte sobre la vida, en la indisolubilidad de arte y vida, ha estado latente, cuando menos desde mediados del s. XIX, en la cartografía intelectual de Occidente. Éste ha impregnado enteramente el estilo de vida de unas privilegiadas minorías afincadas en el espacio de la cultura que, a contracorriente y vistos los efectos concomi- 
tantes a la racionalidad puesta en marcha por la modernidad sobre el "mundo de la vida", se afanarán por resignificar la singularidad expresiva del yo, su apertura a la individualidad estética. Hasta aquí, parafraseando el Eclesiastés, poco nuevo bajo el sol.

Ocurre, sin embargo, que, para nuestro asombro, este añorado proyecto de transfiguración de la vida en una singularizada obra de arte parece haberse democratizado, aparentemente, de tal modo que habría acabado por convertirse en una inequívoca seña de identidad de la época, $\mathrm{y}$, a la postre, no logrando evadir una actitud de reserva en torno suyo. Lo que en el curso del itinerario histórico occidental fuera patrimonio restringido de una cierta aristocracia, de reducidos círculos intelectuales y artísticos, de grupos aglutinados en torno a herméticas sapientias y de una libertina bohemia ha llegado a ser sorprendentemente redefinido como proyecto vital cargado de autenticidad para un extenso umbral de la población occidental. Pues bien, ¿qué tendrá esto que ver con la creatividad a la que nos interpela esta obra cuya edición corre a cargo de Celso Sánchez Capdequí?. Pues sin duda mucho, porque la creatividad, vocablo antes orillado por subestimado para su uso sociológico, se ha abrillantado en el espacio académico como correlato asociado a su reciente calado discursivo en cualquier esfera de lo social. Grosso modo ella apunta, aparentemente, a la reincorporación y puesta de relieve de los frutos de la expresividad, de la autotrascendencia, estética del yo en las diferentes vertientes de la experiencia social. A pesar de ello, actualmente la noción aún no se salva de un empleo como vago cliché en donde tienen cabida connotaciones de lo más variopinto. La virtud acaso más relevante de este trabajo aquí reseñado es el aventurarse en el esfuerzo de clarificación de ella, así como en el consiguiente desbroce de la inevitabilidad de sus contradictorias implicaciones sociológicas en el mapa ideológico de nuestro presente. Con todo conviene no silenciar una decisiva variable históricocultural que está en el trasfondo y da pie a la efervescencia de la creatividad: por utilizar el lenguaje acuñado por Ronald Inglehart, la consolidación de unas pautas culturales sobrecargadas de unas orientaciones de sentido de acento postmaterialista. En gran medida, motivadas por la adquisición de amplios sectores sociales en las generaciones más recientes de un nivel de vida en donde, por vez primera en el curso de la historia occidental, se ven privados del hasta ahora sempiterno problema de cómo habérselas con la realidad para satisfacer sus necesidades básicas. Como en la canónica jerarquía motivacional diseñada por Gordon Allport, la emergencia de la creatividad sería síntoma de una cultura que persigue sisificamente la autorrealización, que, por tanto, no se resigna al peaje de la alienación como contrapartida al logro del bienestar económico y la integración social. Sin embargo, sería equívoco interpretar el significado de la eclosión actual de la creatividad como una compensatoria sublimación, a secas, de las soterradas carencias latentes en una formación social. La obra a la que aquí se alude, como una más de sus virtudes, no cae en esta simplificadora trampa tendida para los nostálgicos de facilonas certezas del agrado de quienes se agarran a códigos explicativos desgastados. Por el contrario, sin perder de vista las coordenadas históricas que indudablemente allanan su emergencia, apuesta por examinar la quintaesencia de la fenomenología creativa, así como su inmersión actuante en lo social, desde una vertiente genuinamente antropológica.

En este sentido, no cabe duda que este trabajo pone al desnudo el quid neurálgico sobre el cual en verdad pivota un tratamiento de la creatividad, despejando las nebulosas que pudieran acechar en su abordaje teórico. Este no es otro que una 
irresuelta disonancia entre discursos ambivalentes en torno a ella. El espíritu de fondo del trabajo deja ver que la fuente de esta ambivalencia, de los claroscuros cernidos en torno a la creatividad y de sus habituales confrontadas lecturas surge, en última instancia, de la juxtaposición entre dos registros difíciles de complementar. Por una parte, un registro socio-antropológico que ve en la creatividad una fuerza instituyente de la cual emanaría algo nuevo y disruptivo con respecto al orden social cristalizado. Por otra parte, un registro institucionalizado que recurre a ella como un nuevo formato ideológico que, maquillado de una embrujadora seducción estética, configura un nuevo perfil de la subjetividad adecuado a las nuevas estrategias de dominación en la modernidad avanzada. Ambos registros se tornan no solo contradictorios, sino, diríamos más, atrapados en una irresoluble contradicción.

Así, a contracorriente de lecturas sociológicas marcadas por un excesivo peso mecanicista, en el primer registro, aquel en el que se baraja un reconocimiento y revalorización de un aspecto instituyente profundamente anidado en la creatividad, se la intima con la potencia atesorada en la imaginación colectiva para instaurar "formas sociales" emergentes; en la sintonía de autores contemporáneos como Georg Simmel, Gilbert Durand, Cornelius Castoriadis, Michel Maffesoli o Hans Joas por concitar a quienes han puesto un mayor ahínco sociológico en este empeño, aunque ya tiempo atrás el sufismo con otra gramática había anunciado algo semejante. Y aquí se recalca que la creatividad, en principio borrosa noción donde las haya, sería sinónimo de una apertura a un horizonte de posibilidades que trascienden las actualmente establecidas o de una inesperada recombinación de las posibilidades de facto existentes. Creatividad, contemplada en estos términos instituyentes, sería equivalente a un plus de realidad impulsado por su hermana gemela: la imaginación. En este cuadro, a la creatividad se le asigna una condición ontológica límite o extralímite a la circunscripción de cualquier marco de sentido instituido. Algo análogo al magmático fluir de la imaginación que, en su consustancial "indeterminación", escapa a los infructuosos encorsetados bajo cualquier "determinación". Por eso, la creatividad instituyente es mal avenida con el lenguaje racional que pretendiera captarla, instrumento por antonomasia de categorización de lo social, y por ende vehículo para la transparencia de éste. De manera que esta creatividad, además de ser familiar a la imaginación, lo es asimismo al arte. Y quizá, debido a esta intrínseca refractariedad de la creatividad instituyente al lenguaje racional, resulta sintomático que los dominios circundantes a ella, aquellos que curiosamente el sistema hegeliano había triangulado en cuanto encarnaciones del "espíritu absoluto", también lo sean. Sin duda, la religión (Otto), el arte (Heidegger) y la filosofía (Hadot) son instancias poseedoras de un algo encriptado e indescifrable que se desliza entre la categorización lingüística al uso; a las que habría que añadir, de igual modo, otras intersecciones de la creatividad, también sintomáticamente alérgicas a esta categorización, tales como la locura (Foucault) o la imaginación (Castoriadis). A fin de cuentas, se nos subraya en este trabajo, querámoslo no, sepámoslo ver o no, la creatividad instituyente irriga cualquier praxis colectiva. Ella se explicita, un tanto travestida, en unos escenarios -los que nos acogen- regidos por una cultura post-secular, siembra su semilla fundamentalmente en el territorio que Ernst Cassirer llamó hace ya tiempo como el de las "formas simbólicas" y su presencia es demandada mayormente cuando las estructuras sociales instituidas muestran una manifiesta tendencia a la fosilización.

El trabajo también se concentra en un segundo registro, de tono éste más 
prosaico, que abunda en cómo la creatividad se habría transformado en un nuevo artificioso slogan al cual apela la dinámica organizacional de las instituciones propias del capitalismo, a fin de troquelar funcionalmente unas subjetividades en concordancia con ella; de la mano de su hija bastarda, aunque en modo alguno análoga: la innovación. Palabra mágica que, recubriéndose de una artificiosa retórica, se presenta como el adalid definitivamente resolutivo del conjunto de los innumerables males inercialmente enquistados en el concierto de las instituciones, disfrazando su auténtico rostro: una sofisticación de la racionalidad instrumental. Este es un registro sociológico de impronta sistémica, más cercenado al campo laboral y cincelado en función de una subordinación al éxito en el cumplimiento de los objetivos que las organizaciones e instituciones han decidido cifrarse. Por tanto, claramente exento de una fidelidad a lo antropológico -a una antropología de signo fundamentalmente simbólico-, y a ciencia cierta por este motivo el más alardeado socialmente. De esta guisa, el llamamiento a la creatividad se vería como una estrategia ideológica perfectamente acomodada a las directrices económicas y políticas características de la modernidad más avanzada, e incluso como un dispositivo foucaultiano instado por un propósito normalizador ligado a un subrepticio incremento de control social. Y esta operatividad trucada bajo el encumbre de una re-estetización de la experiencia en lo que ella contiene de una fetichizada originalidad objeto de un sistemático deprecio tradicional por parte de las lógicas institucionales. La creatividad, así vista, trabajaría en el ámbito de eso que se ha dado en llamar "la cultura" -el relativo a los significados colectivamente compartidos- como estructurante de las subjetividades y con el ánimo de construir una hegemonía sistémica en el sentido de Antonio Gramsci. En absoluto para reavivar, como en el registro anterior, unas adormecidas energías imaginativas dislocantes del orden instituido. Richard Florida, emblemático representante en la utilización funcional de este registro, realizó una célebre llamada a la creatividad, pero en donde la supeditación de ésta a la eficacia no se haya rota ni pretende romperse. En el mismo clima epocal, Luc Boltanski y Eve Chiapello hallan en los discursos que rodean a la creatividad, campeando exitosamente en el seno de las organizaciones, una sibilina mutación en las fórmulas discursivas encaminadas al ejercicio de la dominación, ya definitivamente inservibles y en desuso otras fórmulas pretéritas. Es más, aquello que realmente pondría al descubierto la degradada naturaleza de la versión de la creatividad que en este registro se manejaría radica en el carácter imperativo con el cual ella, cada vez menos enmascaradamente, ha acabado por proponerse como uniforme dictado social.

Celso Sánchez Capdequí coordina sabiamente esta obra, además de correr a su cargo la edición. Teórico social quien, desde hace dos décadas, se ha volcado en una reflexión consagrada a la revitalización de la trascendencia sociológica de las "matrices de significación" articuladoras de las orientaciones de sentido colectivas con un mayor peso en la modernidad avanzada, no siempre lo suficientemente valoradas en la ciencia social. El trabajo se desglosa en tres apartados diferenciados. En el primero se abordan los precedentes sociológicos comportados en la tematización del fenómeno de la creatividad desde una aproximación alineada en la perspectiva de una Sociología de la cultura cuyo punto de mira sigue anclado en la modernidad como objeto, incluyendo una compilación de textos pertenecientes a sociólogos de un especial renombre. Algunos de ellos más clásicos, como es el caso de Castoriadis, y otros más próximos como Merlin 
Donald y Shmuel N. Eisenstadt, o dentro de nuestras fronteras Josetxo Beriain. El segundo apartado compendia un heterogéneo elenco de aportaciones teóricas. En primer lugar, acoge una selección de textos de lo más granado de la sociología clásica centrados, directa o indirectamente, en la temática de la creatividad: Karl Marx, Émile Durkheim, Max Weber, Georg Simmel y Niklas Luhmann. En segundo lugar, incluye una selecta serie de textos extraídos de la obra de sociólogos actuales interesados en una elucidación hermenéutica del significado social de la creatividad en nuestros días: Hans Joas, Wolfgang Knöbl y Jeffrey Alexander. Un último apartado estaría compuesto por una constelación de propuestas cuyo eje vertebrador será una analítica de la inserción de la creatividad en una pluralidad de ámbitos de la experiencia social, tales como el arte, el urbanismo, la economía, el mundo empresarial y los valores. Aquí se integrarían las contribuciones teóricas de un conjunto de sociólogos con una acusada resonancia actual, tales como Andreas Reckwitz, Charles Landry, Luis Enrique Alonso, Carlos Jesús Fernández
Rodriquez, José Angel Bergua Amores y el mismo Sánchez Capdequí.

Como colofón, señalar una última virtud de este trabajo: dejar abierta una interrogante en torno a qué podrá deparar, en su deriva, la irresoluble tensión entre los dos registros de creatividad glosados. Por una parte, hay indicios lo suficientemente fiables de que la creatividad instituida ha emprendido un tesón por capturar, metabolizar y servirse de la creatividad instituyente para sus fines. Paralelamente, en la liberación, también constatable, de esta última se alberga la capacidad de actuación y modificación sobre las formas fisonómicas de la primera, dado que es impensable que, a día de hoy, ella pueda ser enclaustrada intramuros al estilo de las corrientes místicas instituyentes de la Edad Media. En el proceso de retroalimentación de ambas, enmarcado en el contexto de una sociedad post-secular, se baraja nada menos que las expectativas del perfil que pudiera adoptar el devenir cultural venidero en las sociedades de la modernidad avanzada.

Ángel Enrique Carretero Pasín 
